\title{
Lectura estratigráfica muraria y proyecto arquitectónico: un caso de estudio en Cuenca (Ecuador)
}

\author{
Wall stratigraphic reading and architectural project: a case study in Cuenca (Ecuador)
}

María del Cisne Aguirre-Ullauri

Universidad Católica de Cuenca. Cuenca (Ecuador).

Unidad Académica de Ingeniería, Industria y Construcción, CAT. Research Group

Universidad Politécnica de Madrid, España

José Francisco Pesántez-Pesántez

Universidad Católica de Cuenca. Cuenca (Ecuador).

Unidad Académica de Ingeniería, Industria y Construcción, CAT. Research Group

Universidad Politécnica de Madrid (España)

Carlos Miguel Tapia-Vera

Universidad Católica de Cuenca. Cuenca (Ecuador).

Unidad Académica de Ingeniería, Industria y Construcción.

Aguirre-Ullauri, M. C. Pesántez-Pesántez, J. F y Tapia-Vera C. M. (2021). Lectura estratigráfica muraria y proyecto arquitectónico: un caso de estudio en Cuenca (Ecuador). Revista de Arquitectura (Bogotá), 23(I), 105-II4. https:// doi.org/10.14718/RevArq.2021.3328

\author{
María del Cisne Aguirre-Ullauri \\ Arquitecta, Universidad de Cuenca. Cuenca (Ecuador). \\ Master en Conservación y Restauración del Patrimonio Arquitectó- \\ nico, Universidad Politécnica de Madrid. Madrid (España). \\ https://scholar.google.com/citations?user=ahHBdGoAAAAJ, \\ (D) https://orcid.org/0000-0002-3179-7839 \\ (10) cisne2222@hotmail.com, maguirreu@ucacue.edu.ec \\ José Francisco Pesántez-Pesántez \\ Arquitecto, Universidad de Cuenca. Cuenca (Ecuador). \\ Master en Tecnología en la Arquitectura, Universidad Politécnica de \\ Cataluña. Barcelona (España). \\ https://scholar.google.com/citations?user=VG6q I R4AAAA- \\ J\&hl=es, \\ (1) https://orcid.org/0000-0002-|544-269| \\ (10) jpesantezp@ucacue.edu.ec \\ Carlos Miguel Tapia-Vera \\ Arquitecto, Universidad Católica de Cuenca. Cuenca (Ecuador). \\ (D) https://orcid.org/0000-000 I-6868-4785, \\ (a) Cmtapiav82@est.ucacue.edu.ec
}

\section{Resumen}

La época colonial en la ciudad de Cuenca (Ecuador) dejó huellas indelebles en la urbe, así como diversas transformaciones culturales y arquitectónicas que son objeto de particular interés. El presente artículo expone el análisis y la propuesta de intervención sobre una edificación colonial del centro histórico de la ciudad, con base en la lectura estratigráfica muraria y el dictamen patológico. A partir de estos insumos se evidencian: tres etapas constructivas del bien entre 1816 y 2017; también, el predominio de lesiones mecánicas, físicas y antrópicas, como constantes del detrimento del paisaje urbano histórico de la ciudad, y la demanda de intervenciones emergentes y conservativas. En consecuencia, se diseñan intervenciones constructivas específicas bajo la orientación teórica de corte convencional (español e italiano) y la práctica asociada al conocimiento constructivo local. Al mismo tiempo, se apuesta por la recuperación del patrimonio, con la perspectiva de la adaptación a la contemporaneidad, pero sin descuidar la rigurosidad técnica.

Palabras clave: Arquitectura colonial; arqueología aplicada; dictamen patológico; diseño arquitectónico; intervención patrimonial

\begin{abstract}
The colonial period in the city of Cuenca (Ecuador) left indelible traces in the city, as well as diverse cultural and architectural transformations that are of particular interest. This article presents the analysis and intervention proposal on a colonial building of the historic center, based on the mural stratigraphic reading and the pathological opinion. From these inputs, the following are evidenced: three constructive stages of the property between 1816 and 2017; the predominance of mechanical, physical and anthropic injuries as constants of the detriment of the historical urban landscape of the city, and the demand for emerging and conservative interventions. Consequently, specific constructive interventions are designed under the conventional theoretical orientation (Spanish and Italian), and the practice associated with local constructive knowledge. At the same time, there is a commitment to the recovery of heritage, from the perspective of adaptation to contemporaneity without neglecting technical rigor.
\end{abstract}

Keywords: Colonial architecture; applied archaeology; pathological opinion; architectural design; heritage intervention

Recibido: mayo 3 / 2020

\section{Introducción}

La ciudad de Cuenca es conocida a escala mundial por su centro histórico $(\mathrm{CH})$, exponente de muestras diversas de arquitectura; entre ellas, la colonial. Dicho conjunto abarca modelos monumentales representativos y ampliamente estudiados desde diversas vertientes, mientras los ejemplares de arquitectura menor, usualmente, pasan desapercibidos. Con esta base, desde la cátedra de Teoría e Historia de la Arquitectura, de la carrera de Arquitectura y Urbanismo de la Universidad Católica de Cuenca, y desde el proyecto de investigación Los materiales en el estudio histórico-constructivo-ambiental de los conjuntos históricos. El caso de Cuenca, se plantea el presente estudio sobre una edificación colonial ubicada en el área de Primer Orden del $\mathrm{CH}$, desde la línea adscrita al Dictamen PatológiCo, con asistencia de la norma UNE-EN 41805, y de la arqueología de la arquitectura, desde la lectura estratigráfica muraria y la matriz de Harris.

A partir de los criterios teórico-metodológicos disciplinares, se conforma una valoración crítica que se orienta a los juicios técnicos del ejercicio proyectual. Para el fin investigativo, dichos criterios permiten definir valoraciones y aproximaciones conservativas para el conjunto de lesiones patológicas que, derivadas de acciones y omisiones, 
(1) Figura 1. Estudio diacrónico (1) de usos de los espacios. Fuente: elaboración propia (2020). CC BY-NC

(1) Figura 2. Trama urbana en (1) la que se inserta el caso de estudio. Calle Tarqui, entre Simón Bolívar y Sucre. Fuente: elaboración propia. inciden en el estado de conservación del edificio. A partir de ello, el fin práctico plantea una propuesta técnica de intervención constructiva para la recuperación integral y la legibilidad de las etapas históricas del bien. Al mismo tiempo, se busca la conciliación de la evidencia histórica con las dinámicas actuales; por ello, se recurre al planteamiento de Talaverano et al. (2018, p. 3) respecto de las múltiples secuencias definibles en un bien inmueble. Igualmente, se reconoce que en los ámbitos nacional y local son escasos los estudios de índole semejante; esto evidencia la deficiente relación arquitectura-arqueología, pero también, la invariabilidad y la desactualización de recursos técnicos y proyectuales. De tal modo, las referencias de análisis y aplicación se enmarcan dentro de las experiencias española e italiana, donde la articulación disciplinar es mayor.

Así mismo, por su naturaleza académica, la investigación también recoge como objetivos: 1) facilitar la comprensión y la interpretación del pasado, 2) la sensibilización profesional y 3) establecer la base teórica que observe la arquitectura como producto social (Blanco Rotea, 2017, pp. 1-49) como insumos complementarios; es decir, el esfuerzo desplegado define una aproximación técnica que, al considerar el patrimonio construido desde la instancia histórica, permita evidenciar su capacidad de adaptación a las sucesivas demandas temporales de sus usuarios y configurar una aproximación al cuerpo documental aproximado al tipo monográfico.
Lo anterior se encadena a los niveles de registro implementados desde 2010 por el Gobierno Autónomo Descentralizado de Cuenca, lo que, a su vez, evidencia la demanda no cubierta de llegar a los niveles de catálogo y monografía como hechos diacrónicos que permitan identificar, registrar, proteger y difundir —e intervenir- los bienes patrimoniales de manera rigurosa (Heras, 2016, p. 30), para, a su vez, mejorar la gestión de conocimiento y la intervención crítica propias de la salvaguarda del patrimonio arquitectónico.

Finalmente, lo planteado discurre entre: 1) la presentación y el estudio del objeto arquitectónico; 2) la aplicación metodológica; 3) los resultados, enmarcados dentro de dos vertientes del objetivo de investigación: el conocimiento histórico constructivo y patológico, y las demandas de intervención, y 4) las implicaciones de la propuesta.

\section{El objeto de estudio}

El edificio objeto de estudio se emplaza en la calle Tarqui 8-34, entre Mariscal Sucre y Simón Bolívar. En la historia local, se enmarca dentro de la época colonial, y sujeto a los cambios sociales, políticos, económicos, urbanos y ambientales, reconocibles a través de las huellas físicas acumuladas y de la riqueza de conocimiento de la ciudad oculta y los traumas vividos. A priori, el caso de estudio, como parte de un poco visible conjunto arquitectónico, ha dado respuesta a las necesidades familiares, sin transgredir su esencia como patrimonio cultural.
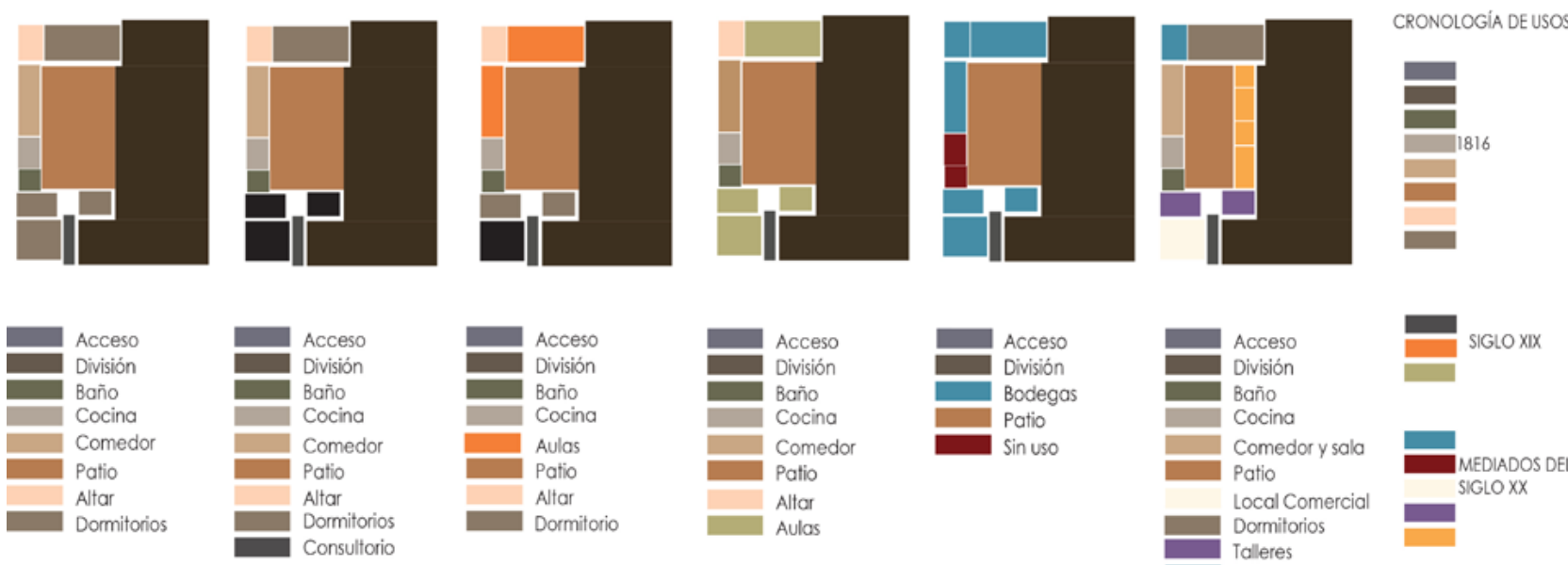

ESTUDIO_TRAMA CALLE TARQUI
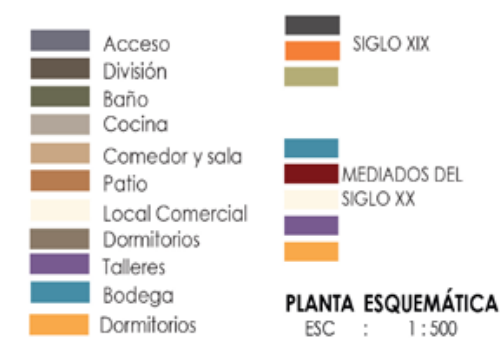

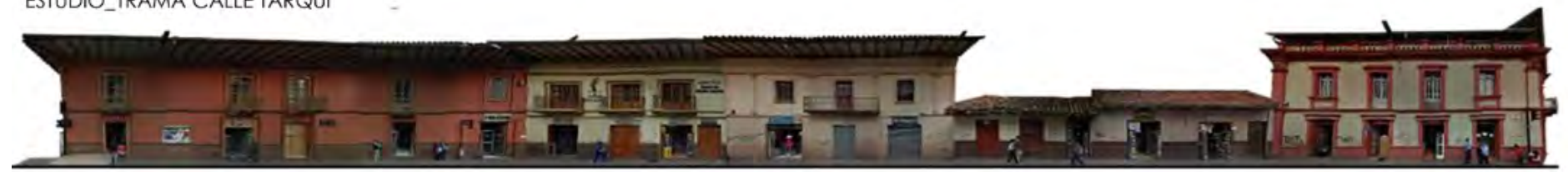

TEXTURAS - COLORES
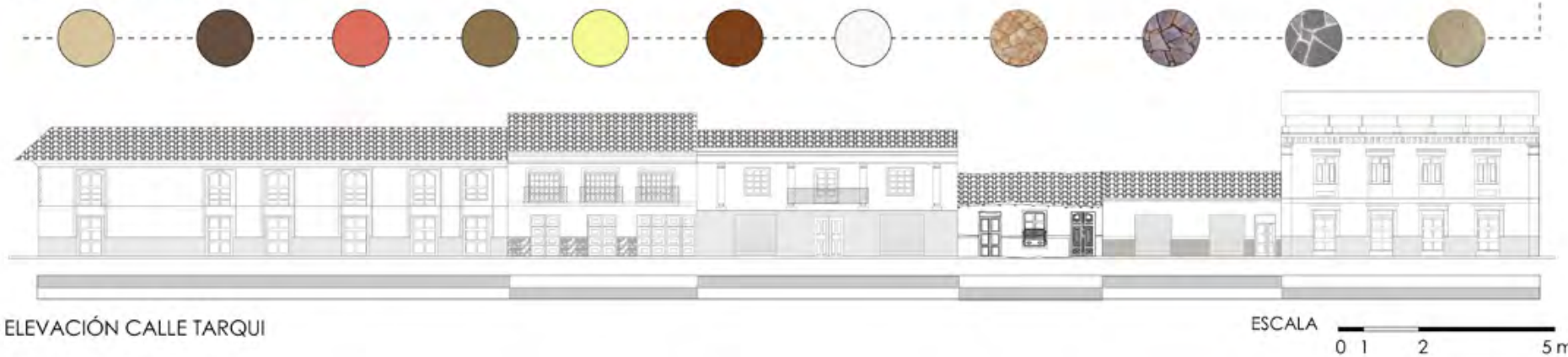
La adecuación de ambientes y la implementación de materiales industrializados destacan como los incidentes en la imagen edilicia, y han promovido la pérdida de elementos característicos, como osamentas en los pavimentos y textiles en los muros, señales claramente vinculadas a usos previos. Por otro lado, el inmueble entre medianeras se desarrolla en una planta extendida en el lote rectangular. En torno al patio central se define la circulación perimetral; mediante un pasillo, se comunica con el exterior y el interior, así como con los espacios interiores; algunos de ellos, a su vez, interconectados, como se observa en la secuencia de la figura 1.

El sistema constructivo está conformado por muros de carga de adobe $^{1}$ y muros divisorios de bahareque, a los cuales se suma el envigado de madera de la cubierta a dos aguas. No existen canecillos, y el alero muestra enchacleado ${ }^{2}$. Como material complementario, en el campo estético, se encuentran la teja cerámica artesanal, así como elementos de madera que resaltan en las ventanas y las puertas. En los pavimentos, el enduelado ${ }^{3}$ pudo reemplazar a la tierra apisonada.

Desde la dimensión urbano-arquitectónica, el contexto adyacente al inmueble concentra hitos significativos, como la iglesia de El Santo Cenáculo, la propia calle Simón Bolívar, la Clínica Bolívar, las catedrales, la Plaza de San Francisco, la Plaza de San Sebastián y en máxima instancia el propio Barranco del río Tomemba que con las manifestaciones arquitectónicas definen una trama particular, en la que la percepción sensorial determina colores, texturas, sonidos, olores, e incluso, el conjuntos de lesiones posibles de tipificar por su naturaleza y por su factor de incidencia, como se observa en la figura 2. Estas dimensiones inciden sobre el estado del edificio; de ahí la necesidad de considerarlas en el proceso de conocimiento, valoración y actuación.

\section{Metodología}

Estudiar estratigráficamente la evolución constructiva de los edificios históricos constituye un imperativo moral (Brandi, 1988, p. 16; Azkarate Garai-Olaun, 2010, p. 60), por exponer la complejidad histórica que, contenida en fachadas, alzados o secciones, explica la realidad intrínseca a la sociedad, reflejada en la arquitectura como respuesta a fenómenos socioculturales, económicos y políticos. En el presente caso de estudio, y por sus condiciones académicas, se opta por desarrollar la investigación a partir de secciones constructivas, ya que, por la configuración de la

1 El empañete, material fecal de ganado caballar, del cual se aprovecha la fibra.

2 El enchacleado, cama o capa de carrizo y tierra, sobre vigas de cubierta.

3 El enduelado, conjunto de tablas de madera machihembrada, colocadas como pavimento de piso. fachada, exponer la evolución histórico-constructiva del edificio habría sido infructuoso.

Procedimentalmente, el estudio se estructura en dos etapas: la primera, a partir de la aplicación de las estratégicas de documentación arquitectónica planteadas por Estévez (2016). Son puntos de interés: ventanas, puertas, pisos, lesiones patológicas y la materialidad en general; como complemento, se aplica la técnica de cinta corrida, mientras que la caracterización patológica se basa en la norma UNE-EN 41805 (partes 1, 3, 5, 9 y 10 $)^{4}$. La segunda etapa usó el análisis estratigráfico murario, aplicado a secciones longitudinales, para describir el proceso histórico. Talaverano (2014, p. 1) plantea que la documentación gráfica de edificios históricos constituye una de las herramientas más poderosas para la preservación de sus valores culturales materiales, y es la base para su investigación, su conservación y su difusión; es decir, no es solo la etapa previa del análisis, sino que se pueden considerar su propia esencia y una forma de generar conocimiento de manera eficiente (Hidalgo, 2016, p. 27; Bohórquez-Rueda et al., 2020, p. 116). Por ello, el análisis estratigráfico incluye subprocesos que amplían el ejercicio de documentación.

La identificación y la diferenciación de unidades estratigráficas motivan a dividir el edificio en tres bloques. Mediante la observación se diferenciaron 87 unidades estratigráficas murarias (UEM), enumeradas bajo la serie conformada por identificación de la crujía o bloque (A, B o C) y enumeración secuencial (desde 1 en adelante). Se incluye una aproximación inicial a las lesiones patológicas que, por medio del levantamiento fotográfico y de inspecciones de campo, se catalogan en una ficha tipo, según tres grupos de lesiones: físicas, mecánicas y químicas. A continuación se definen las relaciones entre UEM y se construye la matriz de Harris con redundancias, aplicando los principios de estratigrafía arqueológica, enunciados por Edward Harris desde 1991, y adaptados y usados sucesivamente por múltiples investigadores de Europa occidental, como bien lo describen Mileto y Vegas (2019). El ejercicio en sí se desarrolla sobre la sección trasversal, y se procura el ordenamiento sistemático, como se evidencia en la figura 3.

Finalmente, la definición de la matriz de Harris simplificada elimina las redundancias; es decir, las UEM se reducen de 87 a 36. Los principales criterios son la observancia de la materialidad y el proceso constructivo. En adelante, la revisión de criterios propios de la teoría de la restauración, dentro del marco de la restauración moderna, científica y crítica, supone el camino hacia la definición de acciones de intervención.

\footnotetext{
4 Secuencialmente, hacen referencia a: generalidades, estudios constructivos y patológicos, estudio patológico de la estructura, estudio patológico de cubierta y estudio patológico de fachadas no estructurales.
} 


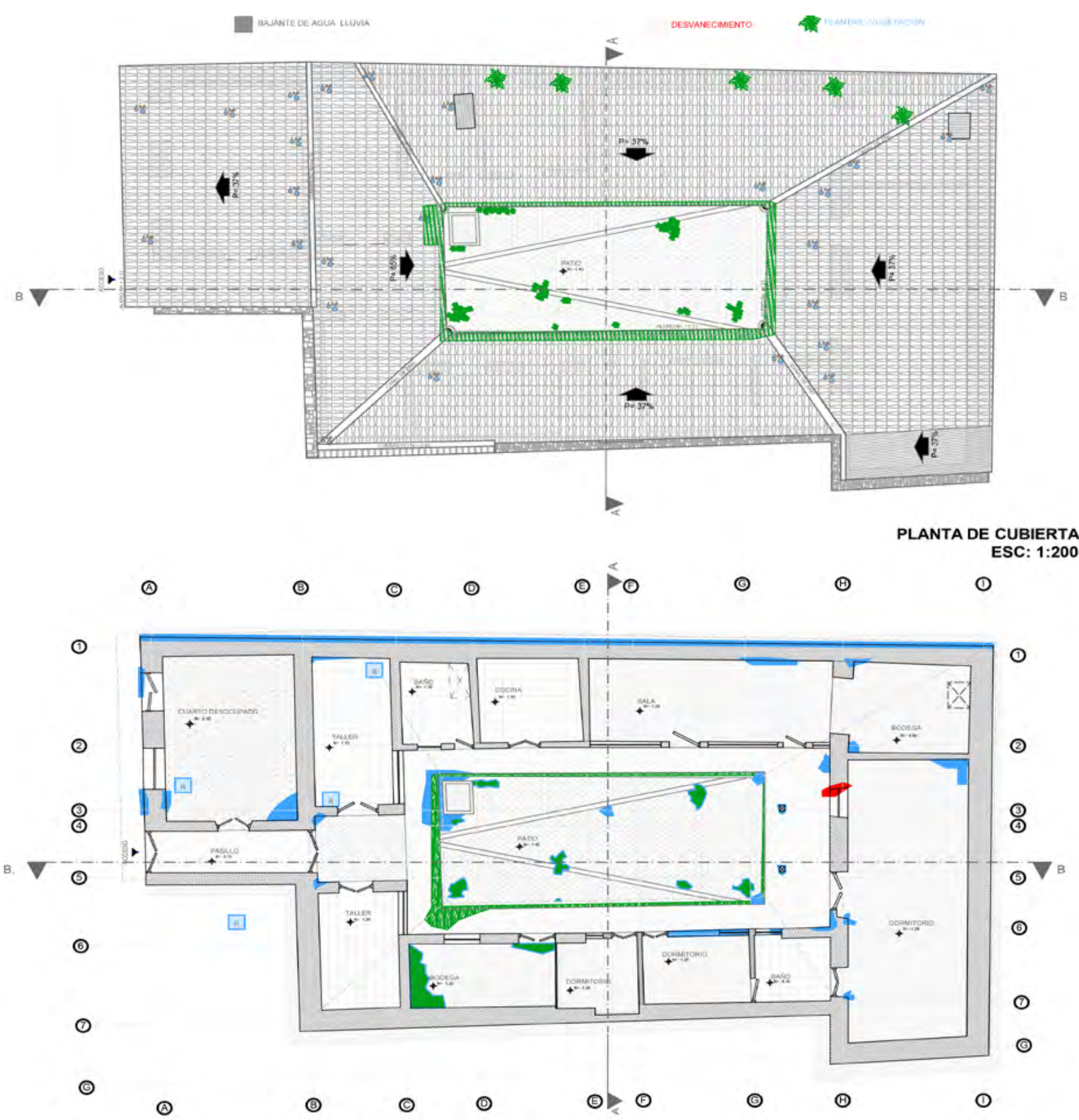

IDENTIFICACIÓN DE LESIONES PATOLÓGICAS

(14) Figura 3. Diagnóstico patológico del caso de estudio. Fuente: elaboración propia (2020). CC BY-NC

\section{Resultados}

\section{Contexto general: el bien inmueble}

Derivadas del análisis estratigráfico, se evidencian las características funcionales y la materialidad del bien, lo cual indica en la figura 3 que el inicio edificatorio - proyectado hacia 1816localiza sus límites físicos en sentido Este-Oeste, con las UEM A1 y C1 (Bloques A y C). Seguidamente, se incorporan los muros de relleno (A3 y C2), de manera conjunta con las vigas de madera (A4 y C4), que, además, forman parte de la estructura de la cubierta, rematada, a su vez, por el enchacleado (A10 y C8), la teja (A8 y C6) y el cumbrero (C11). En la segunda etapa, todavía en el siglo XIX, se agrega el denominado Bloque $B$, desde el muro revocado (B2), seguido de la cubierta (B4), y posteriormente, de la inserción del antepecho enlucido sobre las paredes primigenias. Esta acción deriva en afecciones notorias por su incompatibilidad y por la falta de mantenimiento. Las lesiones patológicas (A5, B7, B9, B11 y C13) no solo evidencian afecciones, sino que ratifican los planteamientos de la matriz de
Harris ilustrados en la figura 3, en cuanto a la disposición temporal de los materiales en el edificio, así como en cuanto a su correspondencia con el proceso histórico de la urbe.

Conforme a la realidad material arquitectónica y urbana, el conjunto de lesiones patológicas incluye: deterioros biológicos, como la presencia de microorganismos, y químicos, tales como corrosión y eflorescencias; también, afecciones físicas, como humedad por capilaridad y filtraciones, desprendimientos, erosión y desvanecimiento de colores, e incidencias antrópicas, como el cambio de materiales. En el conjunto, las lesiones mecánicas presentan la mayor incidencia: se evidencian fisuras, grietas, asentamientos y desplomes. Con esto, la visión técnica previa a la intervención queda contextualizada en términos generales, conforme se ilustra en la figura 3.

Experiencias internacionales destacables desarrollan estos segmentos en paralelo para apoyar la determinación de UEM y de las fases constructivas; en consecuencia, se visualiza que el edificio puede ser entendido desde dos puntos de 


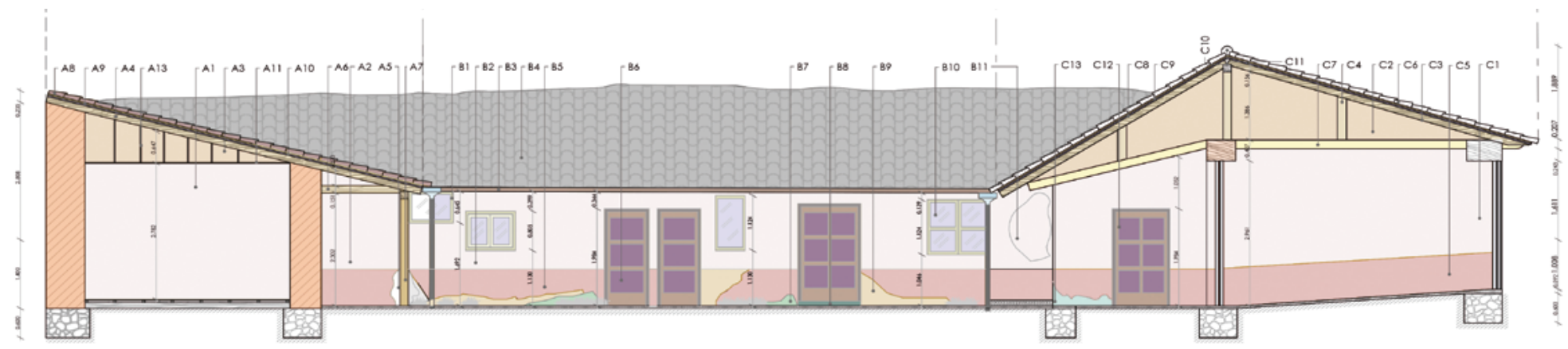

BLOQUE A

Al Muro de adobe

e conrevoque

A3 Muro de rellen

A

A6 Viga de madera de $14 \times 7 \mathrm{~cm}$

A

A9 Viguetas de madera de $14 \times 7 \mathrm{~cm}$

Alo Carizo: enchacleado d: $2 \mathrm{~cm}$

All Estuco

\section{BLOQUE B}

B1 Ventanas de metal - vidrio B3 Canal metálico de $20 \times 20 \mathrm{~cm}$ 34 Teja artesanal de $15 \times 30 \mathrm{~cm}$ En Enlucido de $1.5 \mathrm{~cm}$ de mortero 1:4 B6 Puertas de madera 38 Escalón de piedra 10 Ventanas de madera
BLOQUE C

C1 Muro de adobe C3 Viga de madera de cublerta de $20 \times 20 \mathrm{~cm}$ C4 Tocho de madera de $15 \times 15 \mathrm{~cm}$ C5 Enlucido de $1.5 \mathrm{~cm}$ mortero 1.4 C6 Teja artesanal de $30 \times 15 \mathrm{~cm}$ C8 Carrizo enchacleado d: $2 \mathrm{~cm}$ C9 Tras de madera de $3 \times 2 \mathrm{~cm}$ cada $12 \mathrm{~cm}$ Clo Viga de cumbrero de $20 \times 20 \mathrm{~cm}$ Cl1 Cumbrero de teja de $30 \times 15 \mathrm{~cm}$ C13 Lesión patológica fllu

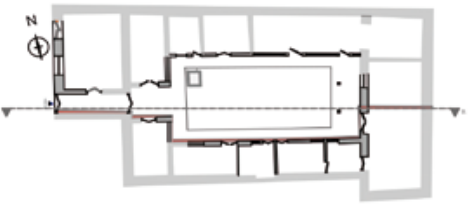

Planta Arquitectónica

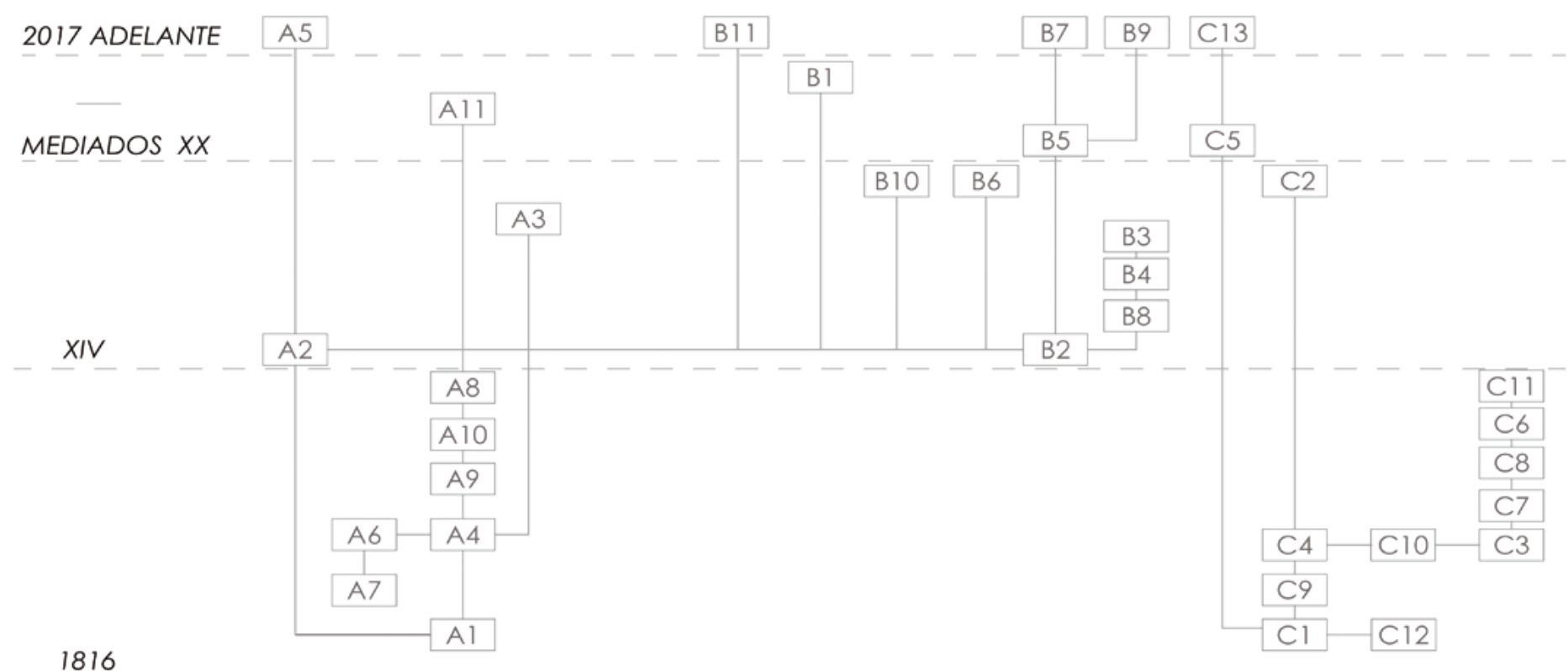

BLOQUE A

vista: primero, desde la intervención como un problema de construcción, de espacio, de contenedor de actividades humanas y otros; y según González-Álvarez y Alonso González (2019), como problema de las biografías y de la memoria cultural de los asentamientos; y en segundo lugar, desde la conservación como un documento histórico que exige autenticidad de la cultura material (González-Álvarez y Alonso González, 2019, pp. 7-12; Mileto y Vegas, 2019, pp. 2-16). Por otra parte, los resultados típicos provenientes de la aplicación metodológica presentada en la figura 3, así como el ejercicio crítico de atribuir un destino contemporáneo al edificio, plantea el desarrollo de una postura teórica y técnica concreta, que ve la luz mediante la articulación de las preexistencias históricas físicas e inmanentes, y supone la permanencia del bien, a la vez que apuntala su linealidad temporal (Choay, 2007) como estrategia de conservación.

\section{Contexto particular: la propuesta}

Desde el desarrollo histórico de la teoría de la restauración, el insumo tomado para acometer dicha labor toma como base aquello que Choay (2007, p. 198) define como reglas de presentación científica y silenciosa. Incluye, además, componentes expuestos en la Carta de Venecia (1964), como la reversibilidad y la integridad desde lo genuino. También, en términos constructivos, se vincula a los Principios para el Análisis, conservación y restauración de las estructuras del patrimonio arquitectónico (2003). Desde estas directrices, el ejercicio proyectual pretende sumarse como un estrato más propiciando la exposición de los aspectos físicos de los tiempos históricos reconocidos y reconocibles, los valores a ellos atribuidos según la Carta de Nara (1994) y la pátina derivada de su coexistencia.

\section{BLOQUE C}

(4) Figura 4. Matriz de Harris. Estado actual conforme al diagnóstico.

Fuente: elaboración propia (2020). CC BY-NC 


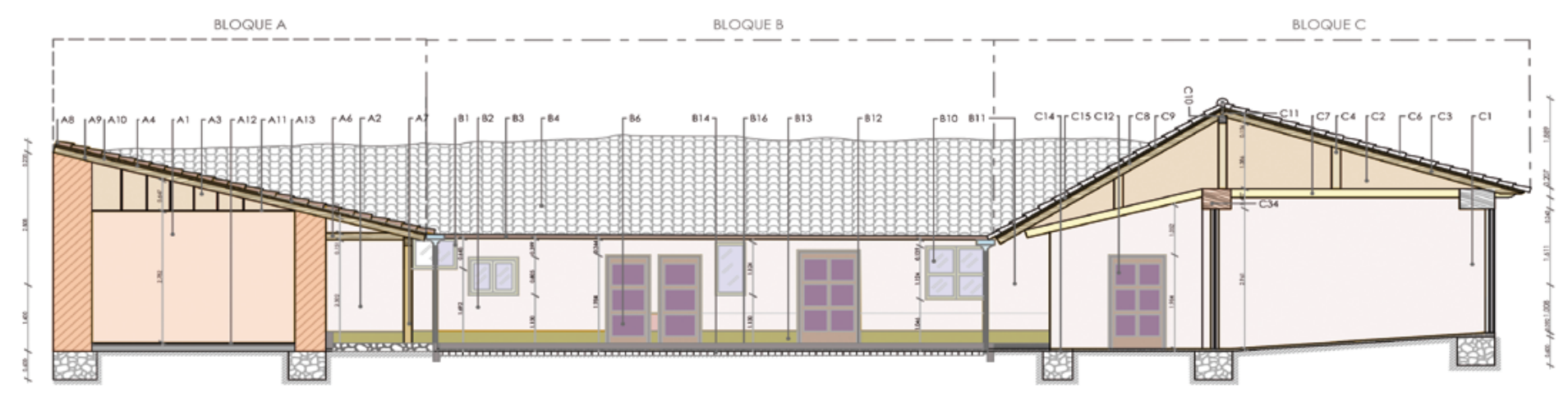

Sección Transversal

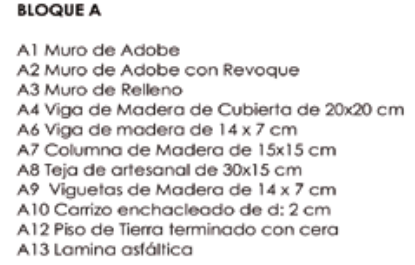

BLOQUE B

B1 Ventanas de metal - vidrio B2 Muro de Adobe con Revoque
B3 Canol Metalico de $20 \times 20 \mathrm{~cm}$ 34 Teja artesanal de $15 \times 30 \mathrm{~cm}$ 86 Puertas de Madera B12 Borde de piedra para patio 13 Borde de piedra superior 814 Piso de Adopsato 316 Piso terminado de Piedra
BLOQUE C

C1 Muro de Adobe con revoque C3 Viga de madera de cubierta de $20 \times 20 \mathrm{~cm}$ C4 Tocho de madera de $15 \times 15 \mathrm{~cm}$ C6 Teja ortesanal de $30 \times 15 \mathrm{~cm}$ 8 Carizo enchacleado de $15 \times 2 \mathrm{~cm}$ C9 Tiras de madera de $3 \times 2 \mathrm{~cm}$ cada $12 \mathrm{~cm}$ clo Viga de cumbrero de $20 \times 20$ Cic Cumbrero de teja de $30 \times 15 \mathrm{~cm}$ C14 Piso terminado de piedra

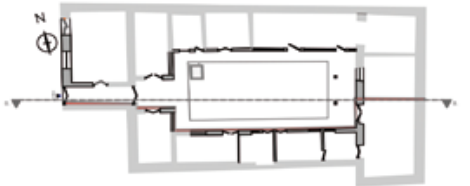

Planta Arquitectonica

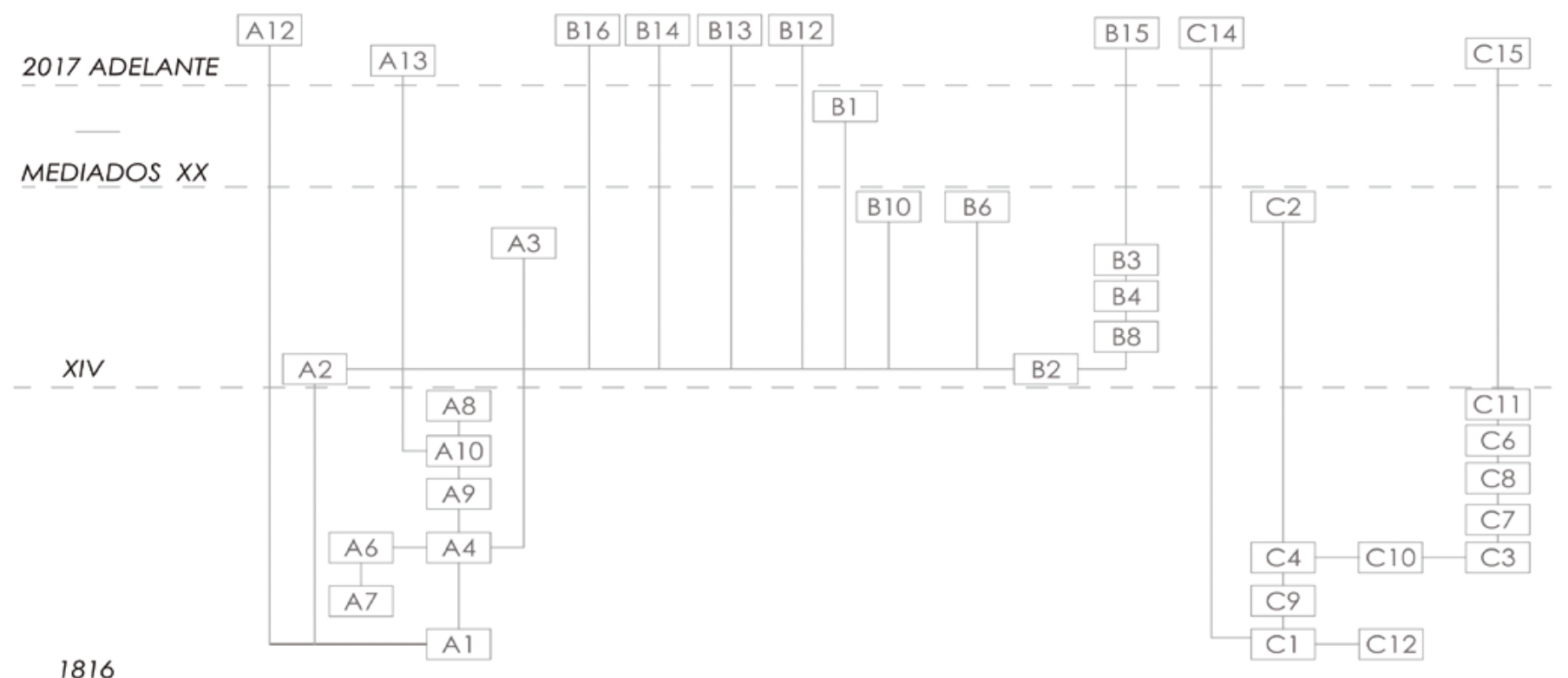

BLOQUE A

La propuesta contemporánea y con vínculos a

(1) Figura 5. Matriz de Harris. Estado posterior a la intervención, según la propuesta.

Fuente: elaboración propia (2020). CC BY-NC los principios teóricos de la conservación arquitectónica propone conservar la evidencia física del paso del tiempo, además de rehabilitar el edificio, como forma de agregar valor respetando su historia adecuándolo para el futuro (Viceconti Nahas, 2010, p. 66) y para la potencialización de usos sociales. Se entiende la posible actuación como un momento histórico más, reconocible en la matriz de Harris, así como discernible desde la gestión con base en los valores reconocibles.

En términos operativos, se incluye, conforme a lo presentado en la figura 5: a) recuperación de pisos interiores exteriores; b) recuperación e integración -interior y exterior - de los pavimentos tradicionales de la época colonial, consistentes en pavimentos (rectangulares o cuadrados) de piedra con osamentas de animales; c) labores de conservación de la cubierta existente, y d) recuperación de los muros de bahareque desde la cimentación, y que pueden tener como soporte una placa flotante o zapatas individuales en la estructura (Garzón, 2015, pp. 658-667).

En sentido amplio, se definen las intervenciones indicadas en la figura 6, y descritas a continuación. Bajo la cota 0 , ilegibles en términos estratigráficos murarios, pero necesarios para la estabilidad y la conservación del bien, se considera la cimentación, compuesta por un dado de hormigón $(0,70 \times 0,70 \times 1,00 \mathrm{~m})$, al cual se ancla, mediante espárragos, una placa metálica $(0,20 \times 0,20 \times 0,004 \mathrm{~m})$, conectada, a su vez, a la columna de madera, con pernos (2"), y conforma así un pórtico con separaciones $(1,50$ $\mathrm{m})$, para integrar las estructuras maestras con los elementos auxiliares. Sobre la cota $0-y$ por tanto, legibles en términos estratigráficos - se incluyen en UEM A12 una capa de pavimento natural compactado $(20 \mathrm{~cm})$, grava $(20-15 \mathrm{~cm})$, un manto de suelo (cemento 7-5 cm) y terminado pulido de cera como impregnante protector. En UEM 

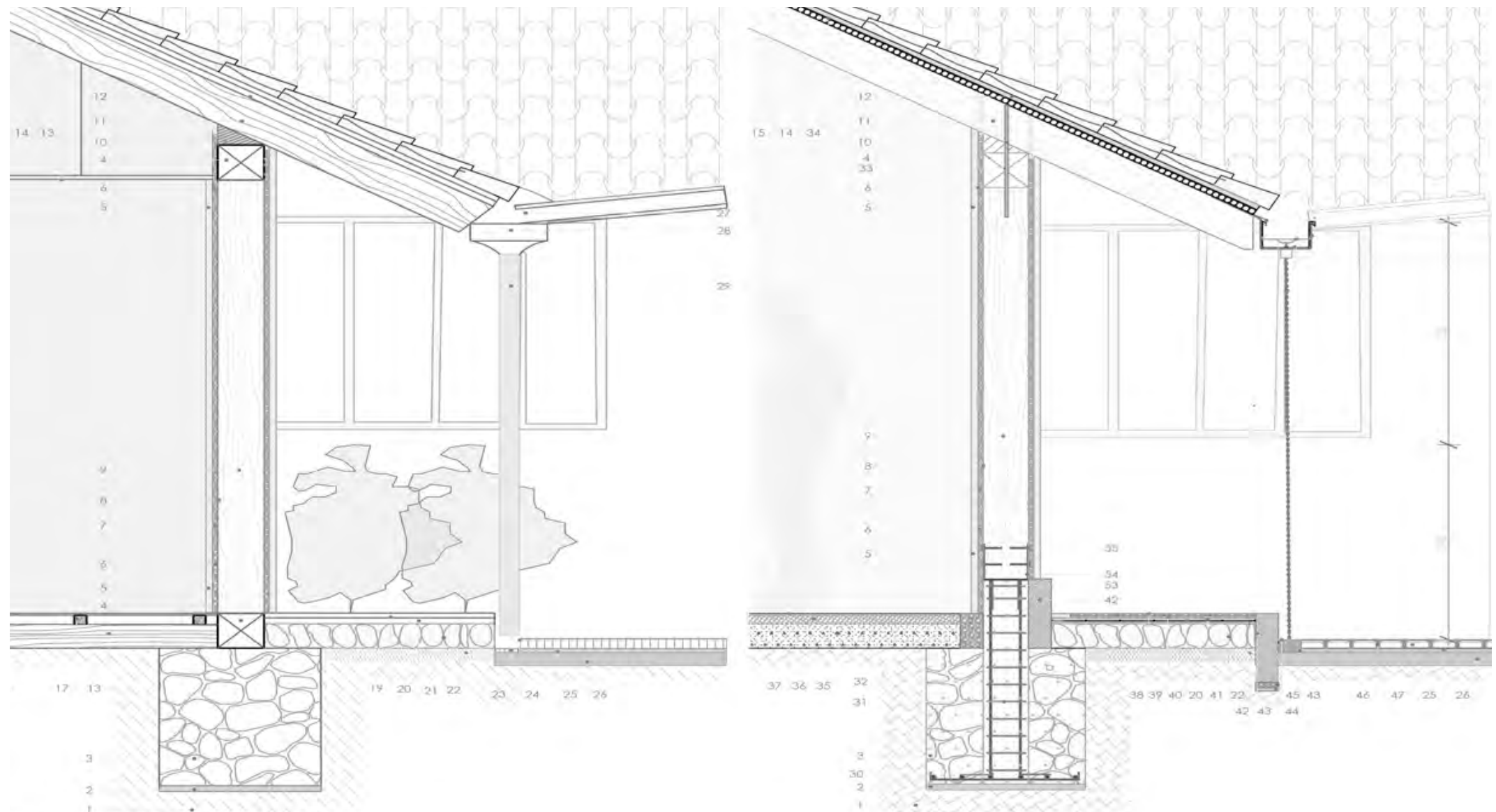

ción estadeoctuah propuesta

YENDA Suelo compactado $20 \mathrm{~cm}$ Cimiento de limpiez Viga de madera de $20 \times 20 \mathrm{~cm}$ Revoque de tierra de $2-3 \mathrm{~cm}$ Malla hexagonal melakca de $0.13 \mathrm{~cm}(1 / 2)$ Tras de madera de $2 \times 4 \mathrm{~cm}$ Columna de madera de $20 \times 20 \mathrm{~cm}$ Unión para viga y columna Tira de de madera de $7 \times 14$ Cielo raso de carrizo e $=1.2 \mathrm{~cm}$ Alambre galvanizado \#18 18

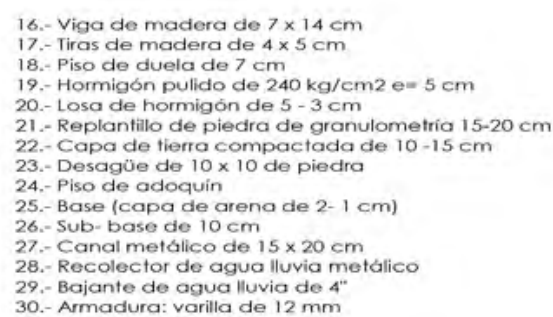

17.- Tiras de madera de $7 \times 14 \mathrm{~cm}$ 6.- - Losa de hormigón de $5-3 \mathrm{~cm}$ - Base (capa de arena de $2-1 \mathrm{~cm}$ ) co de $15 \times 20 \mathrm{~cm}$ 29.- Bajante de agua lluvia de 4

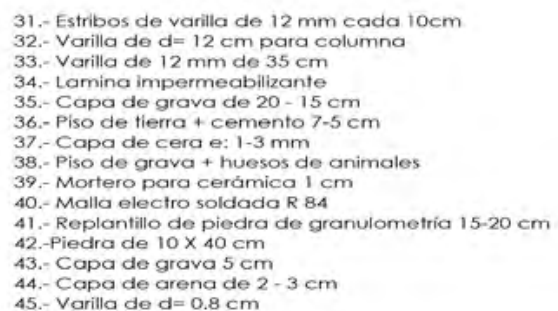

46.- Arena de junta
47.- Adoquin / adopasto 49.- Soporte de canal 50.-Sujetador de cadena
51.- Cadena de $0.15 \mathrm{~cm} \times 0.2$ 52.- Hormigón de $210 \mathrm{Kg} / \mathrm{cm}$ 53.- Espáragas varilla $10 \mathrm{~mm}$ 55.- Pernos de Z' pulg.
B12 se considera una piedra $(40 \times 10 \times 60 \mathrm{~cm})$ que delimitaría el espacio entre el corredor y el patio central, compuesto, a su vez, por una capa de tierra compactada $(20 \mathrm{~cm}$ de espesor, $10 \mathrm{~cm}$ de material pétreo triturado) y un manto de arena $(5 \mathrm{~cm})$, y sobre la cual se dispone el adoquín de tipo adopasto. Por su parte, en la mampostería (UEM A2), conformada por el muro de adobe, se repondría el revoque $(2 \mathrm{~cm}$ de barro y paja de 5-10 cm de largo), empañete de $2 \mathrm{~mm}$ (caolín, guano de caballo, 10\% de resina) y pintura con carbonato de calcio.

Ambos casos se corresponden con la secuencia de intervención entre mediados del siglo XX y 2017. A futuro, y para evidenciar la del primer tipo (bajo la cota 0 ), será necesario recurrir a métodos asociados a la arqueología urbana. Por otro lado, el análisis integrado (Talaverano et al., 2018, pp. 3-5) expone que, al ser grandes las labores de intervención, existen UEM que reemplazan a otras, y su permanencia física resulta inviable.

Al considerar que la tierra como material de construcción puede ser reciclada, su reutilización para preparar los nuevos elementos arquitectónicos permite conservar, en alguna medida, la originalidad de la materia y de las sustancias asociadas (Carta de Nara, 1994). Existen otras unidades (B05) cuya presencia histórica no es relevante: por el contrario, han favorecido el deterioro; se puede definir que su presencia representa una demanda social vinculada al valor instrumental del edificio, por lo que la inserción del nuevo material, considerada una junta constructiva para evidenciarlo, se ilustra en la figura 6. Así mismo, las UEM A11, B05 y C05, por su alto nivel de deterioro, son difícilmente recuperables; incluso, ha llegado a pensarse que su permanencia podría comprometer a corto plazo otros elementos.

\section{Discusión}

La caracterización del caso de estudio como arquitectura menor supone, en la aplicación del método de análisis estratigráfico, un caso aislado, pero necesario. Se pone a consideración la necesidad de difundirlo por fuera de la disciplina arquitectónica, y ensayar segmentos sofisticados del conocimiento material de la arquitectura vernácula y popular, para mejorar la comprensión y la definición de estrategias específicas para su puesta en valor.
(4) Figura 6. Comparativa entre estado actual y la propuesta del caso de estudio.

Fuente: elaboración propia (2020). CC BY-NC 
En cuanto al caso de estudio, el conjunto de transformaciones, definibles como modestas, reflejan la forma de vida, el uso, la ocupación y la convivencia del grupo humano familiar al que se pertenece, y cuyas huellas son visibles a través de los distintos materiales coexistentes y las ausencias identificables, que se muestran en la figura 4. Esta realidad define al bien arquitectónico como un ente vivo, y no solo como el reflejo de los episodios constructivos (secuencia histórico-constructiva) y destructivos (secuencia de degradación) que ha sufrido a lo largo de su vida; también, la tipología de los diversos elementos, tanto constructivos como decorativos, que lo conforman, y otros datos históricos cuya memoria sería contrarrestable con la información mediante el análisis documental (Caballero et al., 2008, pp. 8-9).

En el ámbito particular, las relaciones estratigráficas recurrentes —corte, sobreposición y adosamiento- corroboran la simplicidad de la transformación del espacio doméstico, que bien podría extrapolarse hacia el territorio en busca de la definición de patrones específicos, tanto constructivos como sociales e ideológicos. Ejemplos destacables a ese respecto son los ejercicios desplegados por Rolón (2014) en la arquitectura de La Rioja (Argentina), y por Benedet (2012), en el caso de la vivienda colonial porteña. Por otro lado, la contextualización temporal definida entre los últimos años de colonia y los inicios de la república, y extendido hasta el día de hoy, evidencia que, en atención a su tipo arquitectónico, no se exponen cambios trascendentales que muchos otros ejemplares arquitectónicos experimentaron en la urbe; en especial, desde la segunda mitad del siglo XIX, con la llegada del afrancesamiento y de otras corrientes estilísticas. Por su parte, la vivienda se adapta con mínimos recursos materiales a las demandas de sus ocupantes; destaca, como parte de su autenticidad y su originalidad, la conservación de la integridad material base como recurso recurrente en las transformaciones del espacio arquitectónico. Esta condición fortalece la necesidad de elevar el conocimiento sobre dicha vivienda y la gestión del patrimonio local.

En este contexto, como herramienta, el método estratigráfico es propio para el conocimiento integral, sin llegar a considerarse la panacea de la documentación del patrimonio arquitectónico (Aguirre y Álvarez, 2015, p. 141), pero sí, una estrategia aplicable, que en buenas condiciones permite el debate del conocimiento posicionado y construir argumentación histórica y técnica conjunta con base, así como identificar singularidades de interés y áreas investigativas complementarias. Al decodificar y ordenar desde su complejidad constructiva al edificio (Azkarate Garai-Olaun et al., 2009, pp. 601602), para llegar, a través del entendimiento y del análisis, a la construcción del partido arqui- tectónico superando la visión histórica, o estilística-comparativa, según Benedet (2012, p. 11), así como superar la desestimación permanente de la disciplina arqueológica tan solo como un aval muchas veces administrativo de la intervención $\mathrm{o}$, si acaso, como instrumento de rescate o como labor emergente. Supone una estrategia innovadora, cuya implementación local, en términos prácticos, vislumbra menos acogida que en otras latitudes. Como singular en tal sentido, destaca la Ciudad L'Aquila (Italia), donde dicha estrategia ha figurado como ideal para mitigar lesiones históricas evidenciadas con la actividad sísmica (Marcotulli, 2012, p. 769).

En instancia superior, asimilar y asumir a escala macro el apego por el legado histórico-cultural, trasciende lo monumental, rebasa las nociones únicamente arquitectónicas y demanda a la antropológica como sustento y soporte; pero también, la convergencia de otras áreas, saberes -incluso, enfoques e intereses-, que, como el aprovechamiento social y económico, empodere a los propietarios y a los ciudadanos (Feria Toribio, 2013, pp. 6, 22-23) en general. Delgado (2011, pp. 18, 23) haciendo referencia a las instituciones estatales, indica que los recursos están enfocados en proyectos arqueológicos de rescate, mas no en procesos de investigación. Por el abismo que hay entre arquitectura y arqueología, se limita, ciertamente, toda posibilidad de innovación científica, teórica o práctica.

Al considerar factible la intervención arquitectónica, no debe olvidarse que su ejecución representa, sin duda, la pérdida de indicios y elementos, que en algunos casos pueden todavía aclarar cuestiones sin responder (Azkarate Garai-Olaun et al., 2009), por lo que tomar distancia oportuna permitirá abordar segmentos investigativos relevantes. En el caso estudiado, y a fin de contraponer los usos históricos, sería ideal realizar exploraciones, excavaciones y caracterizaciones del material cultural proveniente del subsuelo, a la manera que Jamieson (2003) aplicó en otros ejemplos locales y contemporáneos, así como la identificación y el análisis de los revestimientos murarios, a fin de ratificar o segmentar las unidades identificadas en las dos primeras etapas constructivas del edificio, como indica la figura 4, sometiendo a evaluación el planteamiento construido frente a la posibilidad de descubrir otros de mayor relevancia, que configuran los valores y la importancia de la trascendencia de la edificación.

Internacionalmente se ha expuesto la dificultad de aplicar el método estratigráfico en entidades revestidas; sin embargo, bajo la premisa de la datación indirecta planteada por Manno$\mathrm{ni}^{5}$ desde la década de los 80, pero poco desarrollado hasta la actualidad, así como el sustento

\footnotetext{
5 Para ampliar el tema, consultar Mannoni (1998).
} 
técnico del caso que ampliaría y garantizaría su aplicación como viable, e incentivar con ello la generación de estudios cronotipológicos, mensiocronológicos y arqueométricos a escala territorial, que eleven su efectividad (Benedet, 2012, p. 22), así como la realización de exploraciones físicas y la asistencia de instrumentación tecnológica, como cámaras infrarrojas, ultrasonidos, esclerómetros y otros (Quirós Castillo, 2014, p. 146), para diferenciar la distribución de materiales bajo los revestimientos, advertir material de interés y apoyar la evaluación estructural y la patología de humedades.

$\mathrm{Al}$ asumir el hecho intervencionista desde otro segmento, es decir, como un proceso cognitivo, se refleja un profundo conocimiento edilicio. Según la Carta de Cracovia, los planteamientos son derivados del ejercicio educativo expuesto, en el cual han convergido valores socioculturales de trascendencia formativa. La propuesta delineada constituye, por un lado, la expresión del equilibrio entre pasado y presente, pero también exhibe una primera aproximación académico-científica, que, incluyendo en una etapa posterior el estudio de los riesgos y las vulnerabilidades del edificio, proyecta la gestión integral propio del momento actual.

Finalmente, en la experiencia abordada, la discusión también se centra en la identificación, la definición y el posicionamiento de los valores propuestos inicialmente por Riegl (1903), pero revisados y acrecentados por Lipe (1984), así como la Carta de Burra (1988), Frey (1997), English Heritage (1997), The Getty Conservation Institute (2002) y otros (por ejemplo, Jaramillo, 2014, p. 36), para definir que la edificación evidencia, desde su evolución histórica, valores de antigüedad e históricos, así como un valor histórico-documental, subjetivo, histórico-artístico y cronístico, y desde su adaptación a la contemporaneidad, valor instrumental, educativo y monetario. La aplicación del método arqueológico en este contexto es de interés, al ser indiscutible el reconocimiento de los acontecimientos constructivos a través del diseño arquitectónico y constructivo para proyectar la intervención de manera íntegra; es decir, a través del reconocimiento de distintos modos de construir, funciones, usos y representaciones simbólicas (Blanco-Rotea, 2017, pp. 2-46), y no solo de los aspectos estilísticos.

\section{Conclusiones}

Al término de la investigación, y conscientes de la impostergable necesidad de intervención material en el edificio, así como de su adaptación a la modernidad, en términos sociales, de uso y económicos, el potencial del método de lectura estratigráfico se presenta como una herramienta crítica para la toma de decisiones, al proveer criterios técnicos para la conservación estratégi- ca del edificio y la aplicación de reglas universalmente reconocidas. Con este planteamiento se pretende materializar a corto o medio plazo una actuación que, con prospectiva, garantice la permanencia del bien patrimonial, su autenticidad y su integridad.

El ejercicio proyectual sobre los insumos documentales generados supone una interpretación crítica y sensible, donde los significados implícitos son potenciados en busca de la reconfiguración o la reestructuración de la identidad material del bien. Se trata, por tanto, de una simbiosis temporal que continúa más allá de sus antecesoras y se codifica en el plano técnico mediante el análisis histórico-constructivo y la definición de criterios para la actuación. Con base en ellos y en el territorio, la estructuración de la propuesta se enmarca dentro del ámbito normativo vigente. Las ordenanzas existentes y sus reglamentos representan lineamientos generales $-y$ por tanto, limitados- para la formulación de posturas técnico-científicas de conservación patrimonial. A falta de una teoría propia, los insumos provenientes de la documentación internacional apoyan la construcción de criterios, aunque el vacío literario expone una necesidad práctica real que debería combatirse.

Cierto es también que, ante este panorama de la gestión del patrimonio cultural en los ámbitos local y nacional, los instrumentos utilizados en el presente trabajo exponen aportes de interés para el conocimiento técnico y la construcción del partido arquitectónico de manera práctica, y con ello, el binomio teoría-práctica que evidencia complementario en lo profesional y lo administrativo.

Finalmente, desde el ámbito académico, como ejercicio de afianzamiento de conocimientos, es una reflexión amplia y profunda, de aprendizaje y autorreconocimiento, así como de difusión del diálogo intercultural e intergeneracional propio del ente arquitectónico que representa a la ciudad. Con ello se evidencia como necesidad la creación de espacios de trabajo multidisciplinar que promuevan la puesta en valor y la diversificación de potencialidades del patrimonio hacia su revitalización sostenible. Al tiempo, se cimienta la base formativa de jóvenes profesionales que, a las puertas del ámbito laboral, deberán saber conjugar el cúmulo de conocimientos para, entre otras cosas, realizar las labores propias de la salvaguarda del patrimonio arquitectónico e histórico a él asociado, en su diversidad tipológica territorial, a la par con las dinámicas mundiales. Es decir, planteando expectativas investigadoras se identifica que existen otros medios de producción de conocimiento y comprensión del patrimonio que, no abordados en la escena local, pueden proveer insumos potentes para su conservación. 


\section{Contribuciones y agradecimientos}

La definición del presente artículo se ha realizado a partir de la siguiente estructura: a) primer autor: contribuciones sustanciales de concepción y diseño, análisis e interpretación de datos, redacción y revisión crítica del artículo, y aprobación final de la versión por publicar; b) segundo autor: análisis e interpretación de datos, y redacción del artículo; c) tercer autor: análisis e interpretación de datos.

\section{Referencias}

Aguirre Ullauri, M. y Álvarez, A. (2015). Análisis histórico constructivo de la iglesia de Santo Domingo de Guzmán (Pajarejos, Segovia) por medio del análisis estratigráfico constructivo, Maskana, 6(1), 131-148. https://doi.org/10.18537/mskn.06.01.10

Azkarate Garai-Olaun, A., Barreiro Martínez, D., Criado Boado, F., García Camino, I, Gutiérrez Lloret, S., Quirós Castillo, J., Salvatierra Cuenca, V. (2009, noviembre 27-30). La arqueología hoy [congreso]. Congreso Internacional Medio Siglo de Arqueología en el Cantábrico Oriental y su Entorno: celebrado en Vitoria-Gasteiz, España. pp. 599-615.

http://rua.ua.es/dspace/handle/10045/31678

Azkarate Garai-Olaun, A. (2010). El análisis estratigráfico en la restauración del patrimonio construido. Dialnet, 51-64.

https://dialnet.unirioja.es/servlet/ articulo? codigo $=3627540$

Benedet, V. (2012). La arquitectura colonial en Buenos Aires. Análisis historiográfiCo, balance crítico y nuevas herramientas para su estudio. Bibliographica Americana. Revista Interdisciplinar de estudios coloniales, 8, 1-31.

https://n9.cl/4eudd

Blanco-Rotea, R. (2017). Arquitectura y paisaje. Aproximaciones desde la arqueología. Arqueología de la Arquitectura, 14(51), 2-46.

http://dx.doi.org/10.3989/arq.arqt.2017.007

Bohórquez-Rueda, J. A., Montañez-Moreno, M. P., y Sánchez-Ávila, W. L. (2020). El dibujo manual y digital como generador de ideas en el proyecto arquitectónico contemporáneo. Revista de Arquitectura (Bogotá), 22(1), 107-117.

https://doi.org/10.14718/RevArq.2020.2660

Brandi, C. (1988). Teoría de la restauración. Editorial Alianza.

Caballero, Z. L., Utrero Agudo, M., Arce, F. y Murillo Fragero, J. (2008). La iglesia de San Miguel de Lillo (Asturias). Lectura de paramentos. 2006. Territorio, Sociedad y Poder Revista de Estudios Medievales, 8(1), 5-80. https://doi.org/10.17811/tsp.0.2008

Choay, F. (2007). Alegoría del Patrimonio. 9na tirada. Gustavo Gili.

Delgado, F. (2011). La arqueología ecuatoriana en el siglo XXI: entre la academia y la Arqueología Aplicada. En Enríquez, K. (ed.), La arqueología y la antropología en Ecuador. Escenarios, retos y perspectivas (pp. 17-40). Abya-Yala.

https://n9.cl/6kq9
Estévez, X. (2016). Método para la recopilación de información de bienes patrimoniales de la ciudad de Cuenca. Edunica.

Feria Toribio, J. (2013). El patrimonio territorial: algunas aportaciones para su entendimiento y puesta en valor. E-rhp. Revista electrónica de patrimonio histórico, 12, 1-25. https://revistaseug.ugr.es/index.php/erph/ article/view/3483/3490

Garzón, L. (2015, noviembre 9-13). Prototipo de vivienda social sostenible. Bahareque prefabricado con tierra, una alternativa técnica, cultural y ecológica. Tierra, sociedad comunidad [congreso]. $15^{\circ}$ Seminario Iberoamericano de Arquitectura y Construcción con Tierra. Cuenca: Universidad de Cuenca. 15, pp. 658-667.

https://dialnet.unirioja.es/servlet/ articulo? codigo $=6086016$

González-Álvarez, D. y Alonso González, P. (2019). Houses and cultural change: An interdisciplinary methodology for exploration of the built environment in contemporary rural Spain. Arqueología de la Arquitectura, 16(85), 2-16. https://doi.org/10.3989/arq.arqt.2019.007

Heras, V. (2016). Cuenca, quince años como patrimonio mundial: evaluación de los procesos de documentación y monitoreo. Estoa, 4(6), 27-35. https://doi.org/10.18537/est.v004.n006.06

Hidalgo, G. (2016). Dibujo y creatividad: relectura de un artículo de Robin Evans. Revista Arteoficio, 12(16), 23-28. http://www.revistas.usach.cl/ojs/index.php/ arteoficio/article/view/2881/2609

Jamieson, R. (2003). De Tomebamba a Cuenca. Arquitectura y Arqueología colonial. Abya-Yala. https://n9.cl/vtqx

Jaramillo, D. (2014). Entorno al patrimonio cultural y su gestión. Universidad y Verdad, 64, 29-42.

https://doi.org/10.33324/uv.v0i64.252

Mannoni, T. (1998). Analisi archeologiche degli edifici con strutture portanti non visibili. Mannoni, Tiziano - All'insegna del giglio. https://www.torrossa.com/it/resources/ an/2908910

Marcotulli, C. (2012). L'analisi stratigrafica muraria e il terremoto: storia sismica degli edifici del "quarto" di S. Giovanni nella città dell'Aquila (XIV-XVIII secolo). Academia, 769-774. https://n9.cl/7zi7m

Mileto, C. y Vegas, F. (2019). Lazos entre arqueología, arquitectura y restauración: cuatro casos y una reflexión, Arqueología de la Arquitectura, 16(87), 3-5. https://doi.org/10.3989/arq.arqt.2019.009

Norma UNE-EN 41805-3 IN de 2009. Diagnóstico de edificios. Parte 1. Generalidades. Comité técnico AEN/CTN 41 Construcción. Madrid, España.

Norma UNE-EN 41805-3 IN de 2009. Diagnóstico de edificios. Parte 3. Estudios constructivos y patológicos. Comité técnico AEN/ CTN 41 Construcción. Madrid, España.

Norma UNE-EN 41805-3 IN de 2009. Diagnóstico de edificios. Parte 5. Estudio patológico de la estructura del edificio. Estructuras de fábrica. Comité técnico AEN/CTN 41 Construcción. Madrid, España.

Norma UNE-EN 41805-10 IN de 2009. Diagnóstico de edificios. Parte 9. Estudio patológico del edificio. Cubiertas. Comité técnico AEN/CTN 41 Construcción. Madrid, España.

Norma UNE-EN 41805-10 IN de 2009. Diagnóstico de edificios. Parte 10. Estudio patológico del edificio. Fachadas no estructurales. Comité técnico AEN/CTN 41 Construcción. Madrid, España.

Quirós Castillo, J. (2014). Contribución al estudio de la Arqueología de la Arquitectura. Arqueología y Territorio Medieval, 1, 141-158. https://doi.org/10.17561/aytm.v1i0.1599

Rolón, G. (2014). Patrones arquitectónicos, clusters constructivos homogéneos y variabilidad en el estudio de edificios históricos. Aspectos técnico formales de la vivienda rural en la provincia de La Rioja (Argentina) durante el período republicano. Arqueología de la Arquitectura, 11(10). https://doi.org/10.3989/arq.arqt.2014.013

Talaverano, R. (2014). Documentación gráfica de edificios históricos: principios, aplicaciones y perspectivas. Arqueología de la Arquitectura, 11(11). https://doi.org/10.3989/arq.arqt.2014.014

Talaverano, M., Cámara, L. y Murillo, J. (2018). Análisis integrado de construcciones históricas: secuencia estratigráfica y diagnóstico patológico. Aplicación en la iglesia de Santa Clara (Córdoba). Arqueología de la Arquitectura, 15, 1-29. https://doi.org/10.3989/arq.arqt.2018.001

Viceconti Nahas, P. (2010). O novo e o velho. A experiência do escritório Brasil Arquitetura nos programas de intervenção em edifícios e sítios históricos. Revista de Arquitectura (Bogotá), 12, 58-67.

https://revistadearquitectura.ucatolica.edu. co/article/view/756 
A Portada: Catedral de Notre Dame de Paris durante los trabajos de reparación en octubre de 2020 Fotografía: Arquitecto Andrés Avila Gómez (octubre, 2020)
(A) Orientación editorial

\section{Enfoque y alcance}

La Revista de Arquitectura (Bogotá) ( (ISSN 1657-0308 Impresa y E-ISSN 2357-626X en línea) es una publicación científica seriada de acceso abierto, arbitrada mediante revisión por pares (doble ciego) e indexada, en donde se publican resultados de investigación originales e inéditos.

Está dirigida a la comunidad académica y profesional de las áreas afines a la disciplina. Es editada por la Facultad de Diseño y el Centro de Investigaciones (CIFAR) de la Universidad Católica de Colombia en Bogotá (Colombia).

La principal área científica a la que se adscribe la Revista de Arquitectura (Bogotá) según la OCDE es:

Gran área: 6. Humanidades

Área: 6.D. Arte

Disciplina: 6D07. Arquitectura y Urbanismo

También se publican artículos de las disciplinas como 2A02, Ingeniería arquitectónica; 5G03, Estudios urbanos (planificación y desarrollo); 6D07, Diseño.

Los objetivos de la Revista de Arquitectura (Bogotá) son:

- Promover la divulgación y difusión del conocimiento generado a nivel local, nacional e internacional

- Conformar un espacio para la construcción de comunidades académicas y la discusión en torno a las secciones definidas.

- Fomentar la diversidad institucional y geográfica de los autores que participan en la publicación.

- Potenciar la discusión de experiencias e intercambios científicos entre investigadores y profesionales.

- Contribuir a la visión integral de la arquitectura, por medio de la concurrencia y articulación de las secciones mediante la publicación de artículos de calidad.

- Publicar artículos originales e inéditos que han pasado por revisión de pares, para asegurar que se cumplen las normas éticas, de calidad, validez científica, editorial e investigativa.

- Fomentar la divulgación de las investigaciones y actividades desarrolladas en la Universidad Católica de Colombia.
Palabras clave de la Revista de Arquitectura (Bogotá): arquitectura, diseño, educación arquitectónica, proyecto y construcción, urbanismo.

Idiomas de publicación: español, inglés, portugués y francés.

Título abreviado: Rev. Arquit.

Titulo corto: RevArq

\section{Políticas de sección}

La revista se estructura en tres secciones correspondientes a las líneas de investigación activas y aprobadas por la institución, y dos complementarias, que presentan dinámicas propias de la Facultad de Diseño y las publicaciones relacionadas con la disciplina.

Cultura y espacio urbano. En esta sección se publican los artículos que se refieren a fenómenos sociales en relación con el espacio urbano, atendiendo aspectos de la historia, el patrimonio cultural y físico, y la estructura formal de las ciudades y el territorio.

Proyecto arquitectónico y urbano. En esta sección se presentan artículos sobre el concepto de proyecto entendido como elemento que define y orienta las condiciones proyectuales que devienen en los hechos arquitectónicos o urbanos, y la forma como estos se convierten en un proceso de investigación y nuevo de conocimiento. También se presentan proyectos que sean resultados de investigación, los cuales se validan por medio de la ejecución y transformación en obra construida del proceso investigativo. También se contempla la publicación de investigaciones relacionadas con la pedagogía y didáctica de la arquitectura, el urbanismo y el diseño.

Tecnología, medioambiente y sostenibilidad. En esta sección se presentan artículos acerca de sistemas estructurales, materiales y procesos constructivos, medioambiente y gestión, relacionados con los entornos social-cultural, ecológico y económico.

Desde la Facultad. En esta sección se publican artículos generados en la Facultad de Diseño, relacionados con las actividades de docencia, extensión, formación en investigación o internacionalización, las cuales son reflejo de la dinámica y de las actividades realizadas por docentes, estudiantes y egresados; esta sección no puede superar el $20 \%$ del contenido.

Textos. En esta sección se publican reseñas, traducciones y memorias de eventos relacionados con las publicaciones en Arquitectura y Urbanismo.
A Frecuencia de publicación

Desde 1999 y hasta el 2015, la Revista de Arquitectura (Bogotá) publicó un volumen al año, a partir del 2016 se publicarán dos números por año en periodo anticipado, enero-junio y julio-diciembre, pero también maneja la publicación anticipada en línea de los artículos aceptados (versión Post-print del autor).

La Revista de Arquitectura (Bogotá) se divulga mediante versiones digitales (PDF, HTML, EPUB, XML) e impresascon un tiraje de 700 ejemplares, los tiempos de producción de estas versiones dependerán de los cronogramas establecidos por la editorial.

Los tiempos de recepción-revisión-aceptación pueden tardar entre seis y doce meses dependiendo del flujo editorial de cada sección y del proceso de revisión y edición adelantado.

Con el usuario y contraseña asignados, los autores pueden ingresar a la plataforma de gestión editorial y verificar el estado de revisión, edición o publicación del artículo.
(A) Canje

La Revista de Arquitectura (Bogotá) está interesada en establecer canje con publicaciones académicas, profesionales o científicas del área de Arquitectura y Urbanismo, como medio de reconocimiento y discusión de la producción científica en el campo de acción de la publicación.

Mecanismo

Para establecer canje por favor descargar, diligenciar y enviar el formato: RevArq FP20 Canjes

Universidad Católica de Colombia
(202I, enero-junio). Revista de
Arquitectura (Bogotá), 23(I),
I-I24. Doi: 10.14718

ISSN: I657-0308
E-ISSN: 2357-626X
Especificaciones:
Formato: $34 \times 24 \mathrm{~cm}$
Papel: Mate II5 g
Tintas: Negro y policromía

Contacto

Dirección postal:

Avenida Caracas No. 46-72

Universidad Católica de Colombia

Bogotá D. C., Colombia

Código postal: 111311

Facultad de Diseño

Centro de Investigaciones (CIFAR)

Sede El Claustro. Bloque "L", 4 piso

Diag. 46A No. 15b-10

Editor, Arq. César Eligio-Triana

Teléfonos:

+57 (1) $3277300-3277333$

Ext. 3109; 3112 o 5146

Fax: +57 (1) 2858895
Correo electrónico:

revistadearquitectura@ucatolica.edu.co cifar@ucatolica.edu.co

Página WEB:

www.ucatolica.edu.co

Vínculo Revistas científicas

http://publicaciones.ucatolica.edu.co revistas-cientificas

https://revistadearquitectura.ucatolica.edu.co/ 
Reflexiones en torno a la enseñanza de la arquitectura y el urbanismo en Colombia. Conversaciones con Juan Carlos

m. Pérgolis Valsecchi, René Carrasco Rey y Juan Carlos del

¿ Castillo

Reflections on the teaching of architecture and urban planning in Colombia. Conversations with Juan Carlos Pérgolis Valsecchi, René Carrasco Rey y Juan Carlos del Castillo

웅

La experiencia de caminar en ciudades latinoamericanas

The experience of walking in Latin American cities

Movilidad urbana de la población en la ciudad de Encarnación * Paraguay. Desarrollo urbano y gestión ambiental

$m$ Urban mobility of the population in the city of Encarnación, Paraguay.

这

ษั

La vivienda adecuada financiada según el ingreso.

El discurso de las Naciones Unidas

பं

La arquitectura frente a las innovaciones pedagógicas.

Pervivencia y resignificación de la Escuela Nueva en el Cono Sur Architecture facing the pedagogical innovations. Survival and resignification of the New School in the Southern Cone

Aporte de las competencias investigativas a la integración de saberes curriculares.

Una visión en el escenario de aprendizaje del diseño

arquitectónico

Contribution of research competencies to the integration of curricula knowledge. A vision in the architectural design learning scenario

Adobe como saber ancestral usado en construcciones

N autóctonas de Pore y Nunchía, Casanare (Colombia)

j. Adobe as an ancestral knowledge used in autochthonous constructions $\stackrel{4}{\longleftarrow}$

Paisaje construido y sustentabilidad urbana: huellas

$œ$

El Plan de Transformación de Osorno

Built landscape and urban sustainability: Identity prints of the modern landscape. The Osorno Transformation Plan

Indicadores de sostenibilidad social y su relación con el

$\hat{a}$

ن்

노 caso de estudio en Cuenca (Ecuador)

ن

Confort térmico en vivienda social multifamiliar de clima cálido en Colombia

느 Thermal comfort in multi-family social housing in a warm climate in ن் Colombia
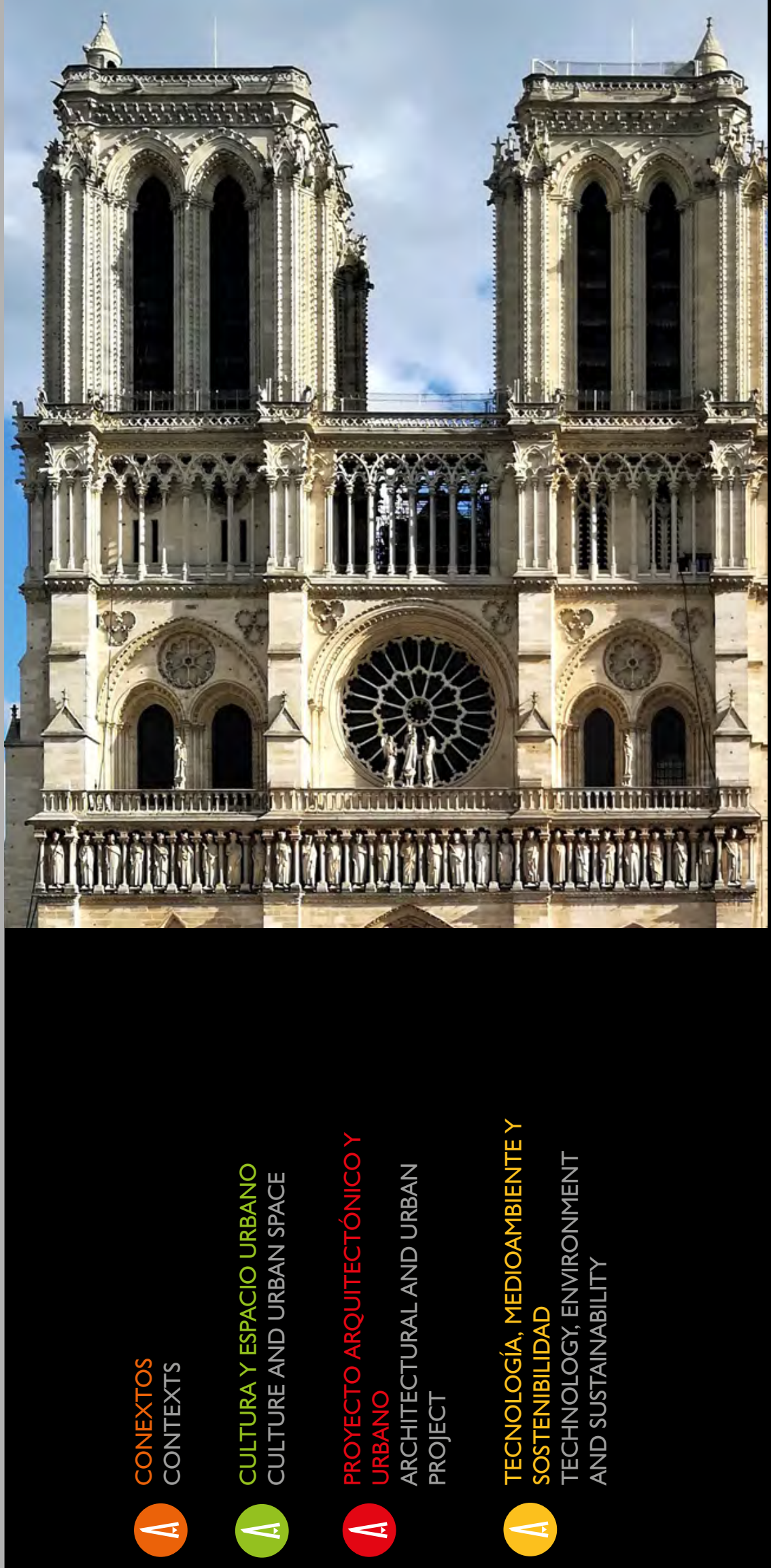

La Revista de Arquitectura es de acceso abierto, arbitrada e indexada y está presente en:
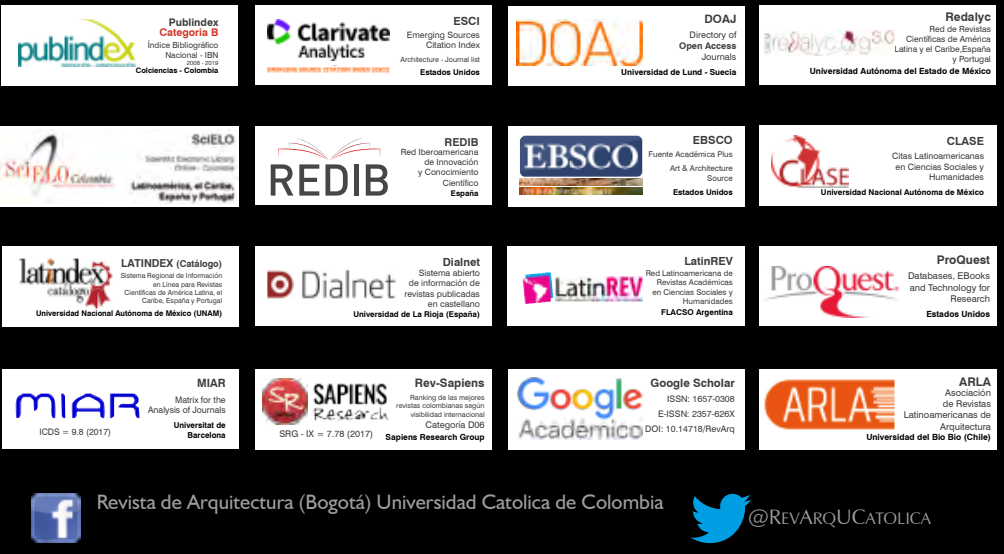

8
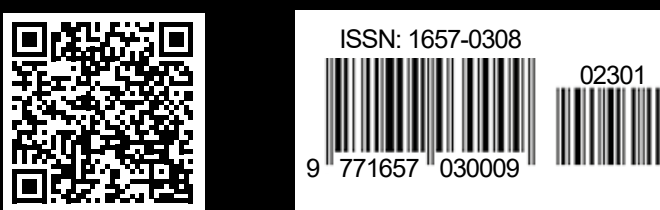